\title{
Osteoclast differentiation antigen, distinct from receptor activator of nuclear factor kappa $B$, is involved in osteoclastogenesis under calcitonin-regulated conditions
}

\author{
T Kukita, A Kukita ${ }^{1}$, T Watanabe and T lijima $^{2}$ \\ Oral Cellular and Molecular Biology, Faculty of Dentistry, Kyushu University, Fukuoka, Fukuoka 812-8582, Japan \\ ${ }^{1}$ Department of Microbiology, Saga Medical School, Saga, Saga 849-0937, Japan \\ ${ }^{2}$ Oral and Maxilofacial Morphology, Faculty of Dentistry, Kyushu University, Fukuoka, Fukuoka 812-8582, Japan \\ (Requests for offprints should be addressed to T Kukita, Oral Cellular and Molecular Biology, Division of Oral Biological Sciences, Faculty of Dentistry, \\ Kyushu University, Maidashi 3-1-1, Fukuoka, Fukuoka 812-8582, Japan; Email: kukitat@dent.kyushu-u.ac.jp)
}

\begin{abstract}
Although calcitonin has been clinically utilized as a primary treatment for several metabolic bone diseases, its inhibitory effects against osteoclastic function diminish after several days owing to the calcitonin 'escape phenomenon'. We have previously found a unique cell-surface antigen (Kat1-antigen) expressed on rat osteoclasts. Here we show evidence that, in the presence of calcitonin, the Kat1-antigen is involved in osteoclastogenesis. Treatment of bone marrow cultures for forming osteoclast-like cells with anti-Kat1-antigen monoclonal antibody (mAb Kat1) provoked a marked stimulation of osteoclast-like cell formation only in the presence of calcitonin but not in its absence. Osteoclastogenesis stimulated by the receptor activator of nuclear factor kappa B (NF- $\mathrm{kB}$ ) ligand/
\end{abstract}

osteoclast differentiation factor was further augmented by $\mathrm{mAb}$ Kat1 in the presence of calcitonin. Furthermore, even in the presence of the osteoprotegerin/osteoclast inhibitory factor, mAb Kat1 induced osteoclast-like cell formation. Our current data suggest that the Kat1-antigen is a molecule that is distinct from receptor activator of $\mathrm{NF}-\kappa \mathrm{B}$. The presence of the unique Kat1-antigen on cells in the osteoclast lineage appears to contribute to the fine regulation of osteoclastogenesis in vivo. Expression of this cell-surface molecule in cells in the osteoclast lineage may partly explain the mechanism responsible for the escape phenomenon.

Journal of Endocrinology (2001) 170, 175-183

\section{Introduction}

Calcitonin, first described by Copp et al. (1962), is a peptide hormone that decreases the blood calcium level. The main target tissues of this hormone are thought to be the kidney and bone tissue, although a high level of expression of the calcitonin receptor (CTR) is observed in the central nervous system (Lin et al. 1991). In bone, osteoclasts express a high level of CTR and administration of calcitonin causes a dramatic decrease in the boneresorbing activity of these cells (Minkin et al. 1971). Morphological observations clearly showed that ruffled borders of bone-resorbing osteoclasts disappeared when the osteoclasts were treated with calcitonin (Kallio et al. 1972). Therefore this peptide hormone is thought to be an ideal reagents for suppressing osteoclast-mediated bone resorption. However, calcitonin's inhibitory effect on bone resorption disappears after continuous administration of this hormone (Wener et al. 1972, Heersche 1992). This phenomenon, known as the 'escape phenomenon', is not well understood although several lines of evidence have suggested that it is to some extent related to the regulation of CTR expressed in osteoclasts. It has been shown that the accumulation of calcitonin in the Golgi apparatus of osteoclasts is related to the down-regulation of CTR (Ikegame et al. 1994). It has also been demonstrated that the synthesis of CTR is suppressed at the transcription level when osteoclast-like multinucleated cells (MNCs) are treated with calcitonin (Takahashi et al. 1995, Findlay $\&$ Martin 1997). Such prolonged down-regulation of the CTR appears to be an important molecular aspect of the escape phenomenon. However, alternative events are also thought to occur in vivo. The escape phenomenon does not occur in irradiated animals (Krieger et al. 1982, Nakamura et al. 1985), suggesting that it requires proliferation of osteoclast progenitors. These studies have hypothesized that newly formed osteoclasts share an important role in the escape phenomenon.

Osteoclasts are multinucleated giant cells that resorb bone. These cells are formed by the cell fusion process among mononuclear precursors of the osteoclasts, i.e. preosteoclasts. Recently, a membrane-bound tumor 
necrosis factor (TNF) family protein, osteoclast differentiation factor (ODF), also called receptor activator of nuclear factor kappa B (NF- $\mathrm{kB}$ ) ligand (RANKL), was found to be an essential cytokine for osteoclastogenesis (Anderson et al. 1997, Lacey et al. 1998, Yasuda et al. 1998, Kong et al. 1999). Before these findings, osteoclast inhibitory factor (OCIF), also called osteoprotegerin (OPG), had been discovered (Simonet et al. 1997). OPG/ OCIF was shown to act as the decoy receptor for RANKL/ODF, causing an inhibition of osteoclastogenesis in vivo as well as in vitro (Lacey et al. 1998, Yasuda et al. 1998).

Previously we found a unique cell-surface antigen distinct from CTR that regulated the function of CTR expressed on rat osteoclasts (Kukita et al. 1994). This antigen, designated Kat1-antigen (Kat1-Ag), is expressed on the cell surface of osteoclasts in a highly specific manner. Morphological studies demonstrated that a high level of Kat1-Ag was expressed on the surface of actively resorbing osteoclasts and newly formed osteoclasts (Kukita et al. 1998). In the present study, we investigated whether Kat1-Ag has a regulatory role in osteoclastogenesis in the presence or the absence of calcitonin. Treatment of bone marrow cultures with anti-Kat1-Ag monoclonal antibody ( $\mathrm{mAb}$ Kat1) resulted in a significant stimulation of osteoclastogenesis only in the presence of calcitonin. These results suggest that Kat1-Ag is involved in osteoclast recruitment in the presence of calcitonin. We have obtained lines of evidence that Kat1-Ag is a molecule distinct from the receptor activator of NF- $\mathrm{KB}$ (RANK), the receptor of RANKL/ODF.

\section{Materials and Methods}

\section{Materials}

Sprague-Dawley (SD) rats were obtained from SEAC Yoshitomi (Fukuoka, Japan). Molecular mass standards for SDS-PAGE were from Daiichi Pure Chemical (Tokyo, Japan). Glutaraldehyde was from Nakalai Tesque (Kyoto, Japan) and paraformaldehyde was from Merck (Darmstadt, Germany). RANKL/ODF (human) and OPG/OCIF (human) were obtained from Pepro Tech Inc. (Rocky Hill, NJ, USA).

\section{Animal treatment}

All experimental animals were maintained in accordance with the Guide for the Care and Use of Laboratory Animals in Kyushu University.

\section{Bone marrow cultures}

Bone marrow cells for forming osteoclast-like MNCs and preosteoclast-like cells were obtained from tibiae and femora of SD rats and cultured as described previously
(Kukita et al. 1993). Briefly, bone marrow cells were obtained from tibiae and femora of SD rats. For forming osteoclast-like MNCs, $10^{6}$ cells were cultured in wells of 24-multiwell culture plates (Becton Dickinson Labware, Franklin Lakes, NJ, USA) in aMEM supplemented with $15 \%$ fetal bovine serum (FBS), 10\% heat-treated rat osteosarcoma ROS 17/2.8 cell-conditioned medium (htROSCM), and $10^{-8} \mathrm{M} 1 \alpha, 25$ dihydroxy vitamin $\mathrm{D}_{3}$ for 4 days. For forming mononuclear preosteoclasts, stromal cell deprived bone marrow cells of $10^{6}$ cells were cultured in aMEM supplemented with $15 \%$ FBS, $10 \%$ htROSCM, and $10^{-8} \mathrm{M} 1 \alpha, 25$ dihydroxy vitamin $\mathrm{D}_{3}$ for 4 days. After fixation with acetone-citrate, the cells were stained for tartrate-resistant acid phosphatase (TRAP) activity by use of an acid phosphatase kit (Sigma Chemical Co., St Louis, MO, USA). TRAP-positive cells having more than three nuclei were counted as osteoclast-like MNCs.

\section{Western blotting analysis}

Rat bone marrow cells were cultured in $100 \mathrm{~mm}$ dishes in $\alpha \mathrm{MEM}$ containing $15 \% \mathrm{FBS}$ in the presence of $10 \%$ htROSCM, $10^{-8} \mathrm{M} 1 \alpha, 25$ dihydroxy vitamin $\mathrm{D}_{3}$ and $10 \mathrm{ng} / \mathrm{ml}$ RANKL/ODF for 4 days. ROS $17 / 2 \cdot 8$ cells were cultured in DME containing 10\% FBS. Cells were fixed in ice-chilled 10\% (w/v) trichloroacetic acid for $60 \mathrm{~min}$, scraped off the plates, and centrifuged at $10000 \mathrm{~g}$ at $4{ }^{\circ} \mathrm{C}$. The pellets were immediately dissolved in $80 \mu \mathrm{l}$ $9 \mathrm{M}$ urea, 2\% (v/v) Triton X-100, 1\% (w/v) dithiothreitol, mixed with $20 \mu \mathrm{l}$ of $10 \%$ (w/v) lithium dodecyl sulfate, completely dissociated by vigorous pipetting and frozen in aliquots at $-80{ }^{\circ} \mathrm{C}$. The protein samples were subjected to SDS-PAGE (13\% polyacrylamide gel, $10 \mu \mathrm{g}$ / lane). Proteins were transferred onto a nitrocellulose membrane. The membrane was immersed in Iscove's Modified Dulbecco's Medium containing 10\% FBS and $1 \mathrm{mM} \mathrm{CaCl}_{2}$ at room temperature for $30 \mathrm{~min}$ and reacted with $\mathrm{mAb}$ Kat1 or control antibodies at room temperature for $60 \mathrm{~min}$. After rinsing in TBS $(\mathrm{pH} 7 \cdot 5)$ containing $1 \mathrm{mM} \mathrm{CaCl}_{2}$, the membrane was fixed in ice-chilled $2 \%$ glutaraldehyde prepared in TBS containing $1 \mathrm{mM} \mathrm{CaCl}_{2}$ for $6 \mathrm{~min}$. The membrane was rinsed in TBS containing $1 \mathrm{mM} \mathrm{CaCl}{ }_{2}$ and then immersed overnight in PBS $(\mathrm{pH}$ $7 \cdot 5)$ containing $10 \%(\mathrm{w} / \mathrm{v}) \mathrm{BSA}$ and $3 \%$ goat serum at $4{ }^{\circ} \mathrm{C}$ to block non-specific binding. Immunoreactive bands were detected by use of biotinylated anti-mouse $\operatorname{IgM}(\mu$ chain specific) and an ABC-AP kit (Vector Laboratories, Bucks, UK).

\section{Statistical analysis}

The number of TRAP-positive cells was counted and each value was represented as the mean \pm s.E. of quadruplicate cultures in 24-well culture plates. All data obtained from bone marrow cultures were analyzed by use of Student's $t$-test and a post-ANOVA test. 


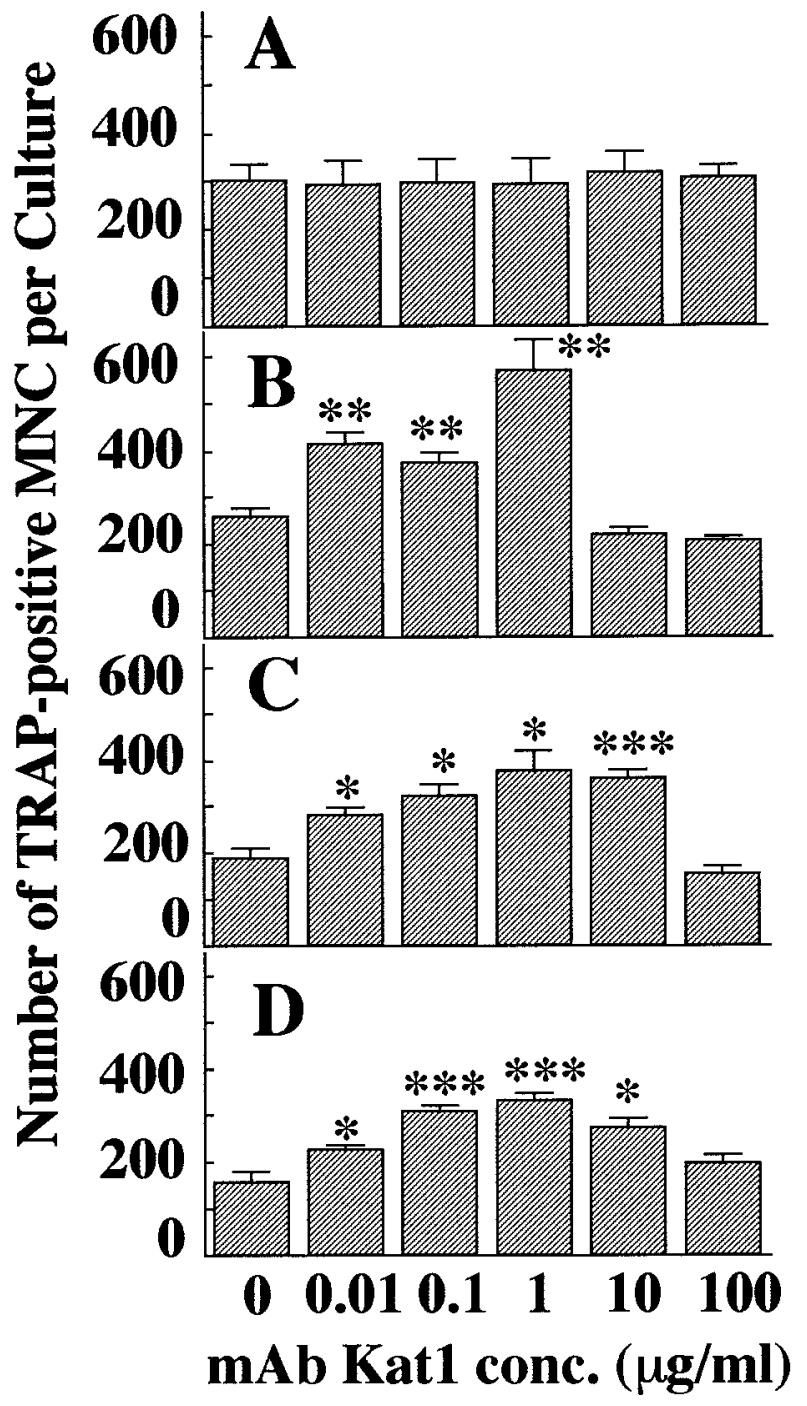

Figure 1 Marked stimulation of osteoclast-like MNC formation by mAb Kat1 only when cells are treated with calcitonin. Bone marrow cells were cultured to form osteoclast-like MNCs in the presence of various concentrations of $m A b$ Kat1 with $(B-D)$ or without $(A)$ calcitonin as described in Materials and Methods. Cells were stained for TRAP on day 4 of the culture and the number of TRAP-positive MNCs counted. (A) Formation of osteoclast-like MNCs was not affected by any concentration of mAb Kat1, in the absence of calcitonin. (B-D) Significant stimulation of osteoclast-like MNC formation was observed in the presence of calcitonin (B 0.01, C 0.1, D $10 \mathrm{ng} / \mathrm{ml}$ calcitonin). Data show the mean number of TRAPpositive MNCs \pm S.E. from quadruplicate cultures in 24-well culture plates. Three independent experiments were performed and similar results obtained. ${ }^{*} P<0 \cdot 05,{ }^{* *} P<0 \cdot 01,{ }^{* * *} P<0 \cdot 001$.

\section{Results}

Stimulation of osteoclastogenesis by treatment of bone marrow cultures with $m A b$ Kat1 in the presence of calcitonin

Figure 1 shows the dosage effect of mAb Kat1 on the formation of osteoclast-like MNCs in the presence of
Table 1 Absence of stimulatory effects of mAb Kat1 on preosteoclast formation in both the presence and absence of calcitonin. Bone marrow cells were depleted of stromal cells and cultured for forming mononuclear preosteoclast-like cells as described in Materials and Methods in the presence of various concentrations of $\mathrm{mAb}$ Kat1 with or without calcitonin. After 4 days of culture, cells were stained for TRAP and the number of TRAP-positive mononuclear cells counted. Data represent means \pm S.E. from quadruplicate cultures. Significant effects of $\mathrm{mAb}$ Kat1 were not observed on the formation of preosteoclast-like mononuclear cells in either the presence or absence of calcitonin

\begin{tabular}{|c|c|c|}
\hline & $\begin{array}{l}\text { mAb Kat1 } \\
(\mu \mathrm{g} / \mathrm{ml})\end{array}$ & $\begin{array}{l}\text { TRAP-positive mononuclear } \\
\text { cells per culture }\end{array}$ \\
\hline Calcitonin $0 \mathrm{ng} / \mathrm{ml}$ & $\begin{array}{l}0 \\
0 \cdot 01 \\
0 \cdot 1 \\
1 \\
10 \\
100\end{array}$ & $\begin{array}{l}171 \cdot 5 \pm 11 \cdot 7 \\
187 \cdot 2 \pm 29 \cdot 0 \\
160 \cdot 5 \pm 20 \cdot 2 \\
144 \cdot 0 \pm 12 \cdot 7 \\
140 \cdot 0 \pm 11 \cdot 1 \\
203 \cdot 7 \pm 20 \cdot 0\end{array}$ \\
\hline Calcitonin $1 \mathrm{ng} / \mathrm{ml}$ & $\begin{array}{l}0 \\
0 \cdot 01 \\
0 \cdot 1 \\
1 \\
10 \\
100\end{array}$ & $\begin{array}{l}161 \cdot 2 \pm 13 \cdot 4 \\
173 \cdot 0 \pm 14 \cdot 0 \\
140 \cdot 7 \pm 24 \cdot 4 \\
150 \cdot 5 \pm 27 \cdot 9 \\
171 \cdot 0 \pm 18 \cdot 8 \\
220 \cdot 5 \pm 20 \cdot 1\end{array}$ \\
\hline
\end{tabular}

various concentrations of calcitonin. In the absence of calcitonin, no significant effect was observed when $\mathrm{mAb}$ Kat1 was added to cultures for forming osteoclast-like MNCs (Fig. 1A). However, in the presence of calcitonin, $\mathrm{mAb}$ Kat1 markedly stimulated osteoclast-like MNC formation (Fig. 1B-D). The peak of the stimulation was around $1 \mu \mathrm{g} / \mathrm{ml} \mathrm{mAb}$ Kat1. Higher concentrations of $\mathrm{mAb}$ Kat1 tended to suppress formation of osteoclast-like MNCs. Control mAbs having the same immunoglobulin class as mAb Kat1 (IgM) showed no significant effect on MNC formation at any concentrations and at any dose of calcitonin (data not shown).

These data strongly suggest that osteoclastogenesis is finely regulated by the cell-surface Kat1-Ag only in the presence of calcitonin. We confirmed that osteoclast-like MNCs formed in the presence of calcitonin and $\mathrm{mAb}$ Kat1 resorbed dentin (data not shown). To determine whether $\mathrm{mAb}$ Kat1 stimulates the formation of preosteoclasts in the presence and absence of calcitonin, we examined the dosage effect of mAb Kat1 on formation of mononuclear preosteoclast-like cells from bone marrow cells depleted of stromal cells (Table 1). Formation of preosteoclast-like cells was not significantly affected by treatment with $\mathrm{mAb}$ Kat1, in either the presence or absence of calcitonin $(1 \mathrm{ng} / \mathrm{ml})$. These data suggest that the multinucleation step was enhanced by the presence of $\mathrm{mAb}$ Kat1 under the suppressed conditions mediated by calcitonin.

\section{Kat1- $A g$ is a molecule distinct from $R A N K$}

The findings that Kat1-Ag is expressed on cells in the osteoclast lineage and is involved in the formation of 


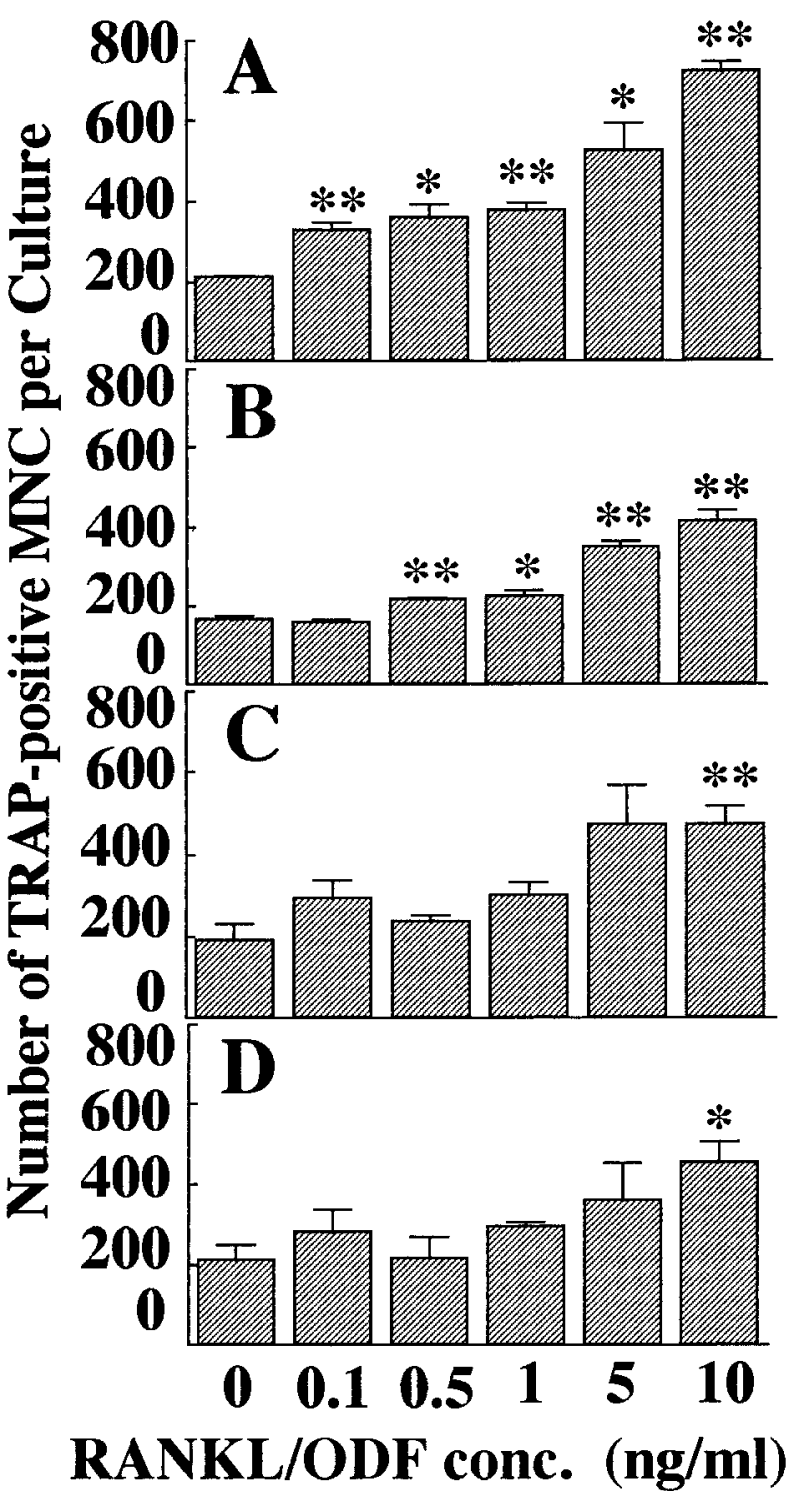

Figure 2 Effect of RANKL/ODF on osteoclast-like MNC formation, in the presence of various concentrations of calcitonin. Bone marrow cells were cultured to form osteoclast-like MNCs in the presence of various concentrations of RANKL/ODF with (B-D) (B 0.01, C 0.1, D $1 \mathrm{ng} / \mathrm{ml}$ ) or without (A) calcitonin.

(A) Osteoclast-like MNC formation was markedly stimulated by the addition of RANKL/ODF, in the absence of calcitonin. (B-D) Suppressed level of stimulation was observed in the presence of calcitonin. Data show the mean number of TRAP-positive MNCs \pm S.E. from quadruplicate cultures in 24-well culture plates. Three independent experiments were performed and almost the same results obtained. ${ }^{*} P<0 \cdot 05,{ }^{* *} P<0 \cdot 01$.

osteoclast-like MNCs raise the possibility that the ligand of Kat1-Ag is RANKL/ODF. In other words, Kat1-Ag might be RANK. To address this question, we have examined the effect of RANKL/ODF on MNC formation in the presence of various concentrations of calci-
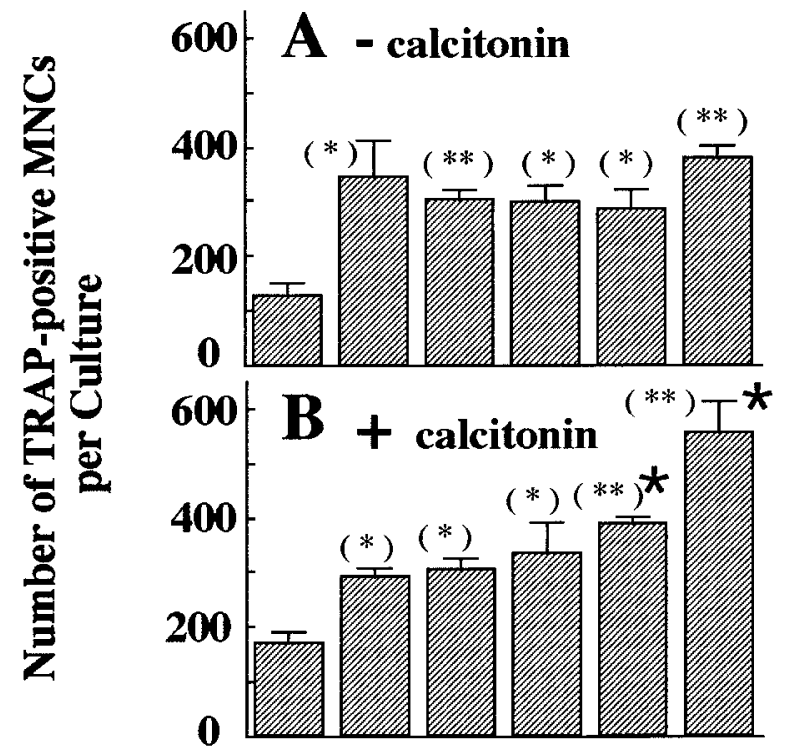

RANKL/ODF

(ng/ml)
mAb Kat1
$(\mu \mathrm{g} / \mathbf{m l})$

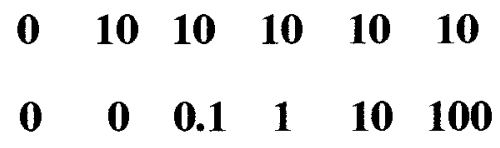

Figure 3 RANKL/ODF-induced osteoclastogenesis was further stimulated by mAb Kat1 only in the presence of calcitonin. Bone marrow cells were cultured in the presence or absence of $10 \mathrm{ng} / \mathrm{ml}$ RANKL/ODF with or without mAb Kat1 in the presence (B) or in the absence (A) of $1 \mathrm{ng} / \mathrm{ml}$ calcitonin. After culture for 4 days, cells were stained for TRAP and the number of TRAP-positive MNCs counted. Data show the mean number of TRAP-positive MNCs \pm S.E. from quadruplicate cultures in 24-well culture plates. Three independent experiments were performed and almost the same results obtained. $\left({ }^{*}\right) P<0 \cdot 05,\left({ }^{* *}\right) P<0 \cdot 01$, based on data of the control cultures obtained in the absence of both RANKL/ODF and mAb Kat1. ${ }^{*} P<0 \cdot 05$, based on data obtained in the presence of $10 \mathrm{ng} / \mathrm{ml}$ RANKL/ODF but without mAb Kat1.

tonin (Fig. 2). RANKL/ODF markedly stimulated the formation of osteoclast-like MNCs in the absence of calcitonin (Fig. 2A). This result is in contrast to the results shown in Fig. 1A, in which no stimulating effect was observed in the osteoclast-like MNC formation in the absence of calcitonin by treatment with mAb Kat1. The stimulatory effect mediated by RANKL/ODF was to some extent suppressed in the presence of calcitonin (Fig. 2B-D). No additional stimulatory effect was observed by treatment with various concentrations of RANKL/ODF, in the presence of calcitonin. We further examined the dosage effect of mAb Kat1 on RANKL/ODF-mediated osteoclastogenesis (Fig. 3). In the absence of calcitonin, RANKL/ODF-induced osteoclast-like MNC formation was not affected by the addition of mAb Kat1 (Fig. 3A and Fig. 4A and B). However, in the presence of $1 \mathrm{ng} / \mathrm{ml}$ 


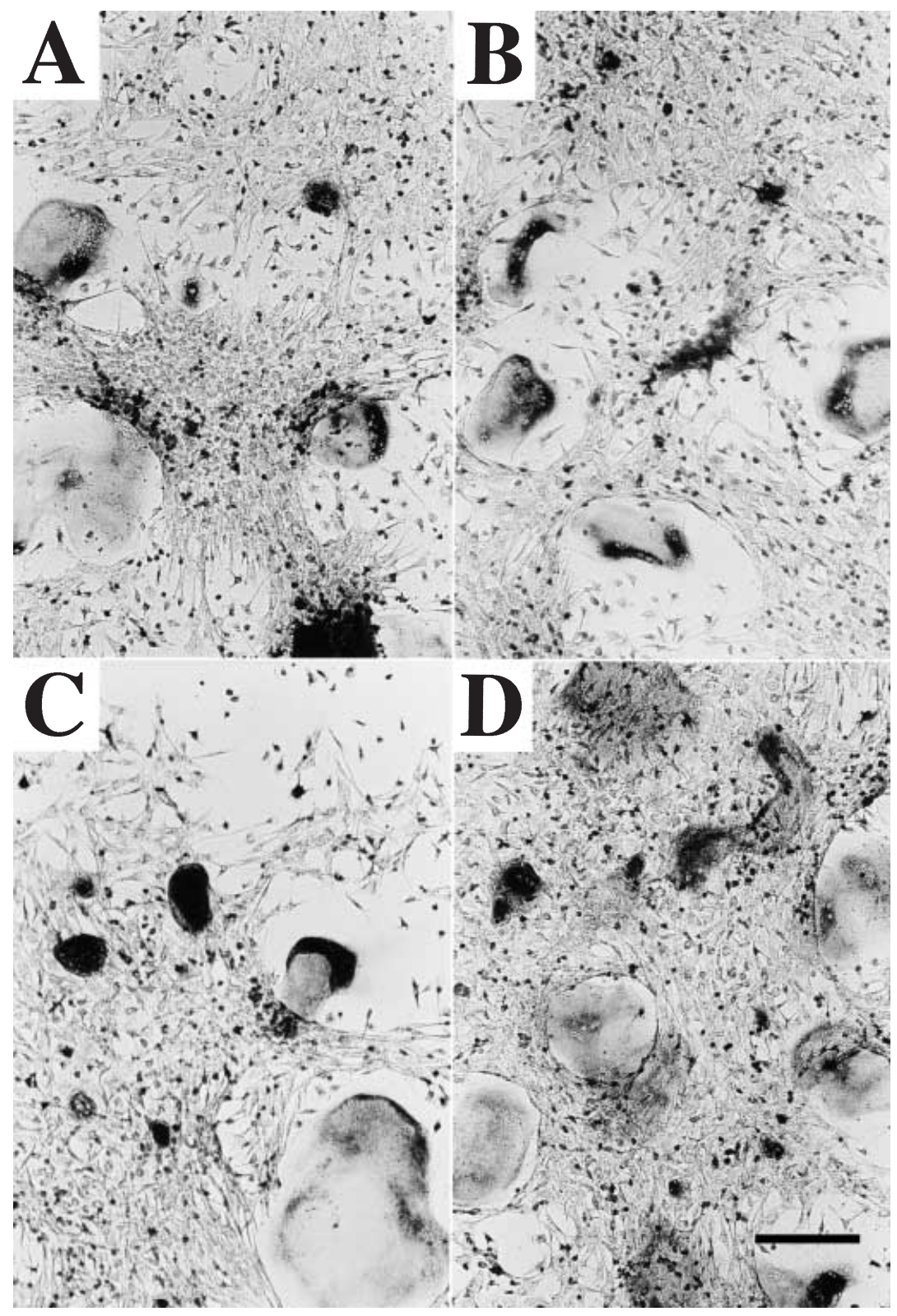

Figure 4 Photomicrographic demonstration of osteoclast-like MNCs induced by RANKL/ODF with or without mAb Kat1. Bone marrow cells were cultured in the presence of $10 \mathrm{ng} / \mathrm{ml}$ RANKL/ODF with $(B, D)$ or without $(A, C)$ mAb Kat1 in the presence $(C, D)$ or absence (A, B) of $1 \mathrm{ng} / \mathrm{ml}$ calcitonin. After culture for 4 days, cells were stained for TRAP and observed under the microscope. Scale bar $200 \mu \mathrm{m}$.

calcitonin, formation of TRAP-positive MNCs was significantly stimulated by treatment with $\mathrm{mAb}$ Kat1 (Fig. 3B and Fig. 4C and D). In comparison with the data in Fig. 1, it required higher concentrations of $\mathrm{mAb}$ Kat1 $(10-100 \mu \mathrm{g} / \mathrm{ml})$ for stimulation of osteoclastogenesis in the presence of RANKL/ODF and calcitonin. Morphology of osteoclast-like MNCs stimulated with mAb Kat1 was similar to that of osteoclast-like MNCs unstimulated with this antibody (Fig. 4).
These data demonstrate that Kat1-Ag-mediated osteoclastogenesis still remained even if cultures were stimulated with RANKL/ODF. These data also indicate that interactions between RANKL/ODF and RANK were not interfered with by $\mathrm{mAb}$ Kat1 and that $\mathrm{mAb}$ Kat1 showed a unique activity in osteoclastogenesis only in the presence of calcitonin.

We further examined the stimulatory effect of $\mathrm{mAb}$ Kat1 on osteoclastogenesis in the presence of OPG/OCIF, 

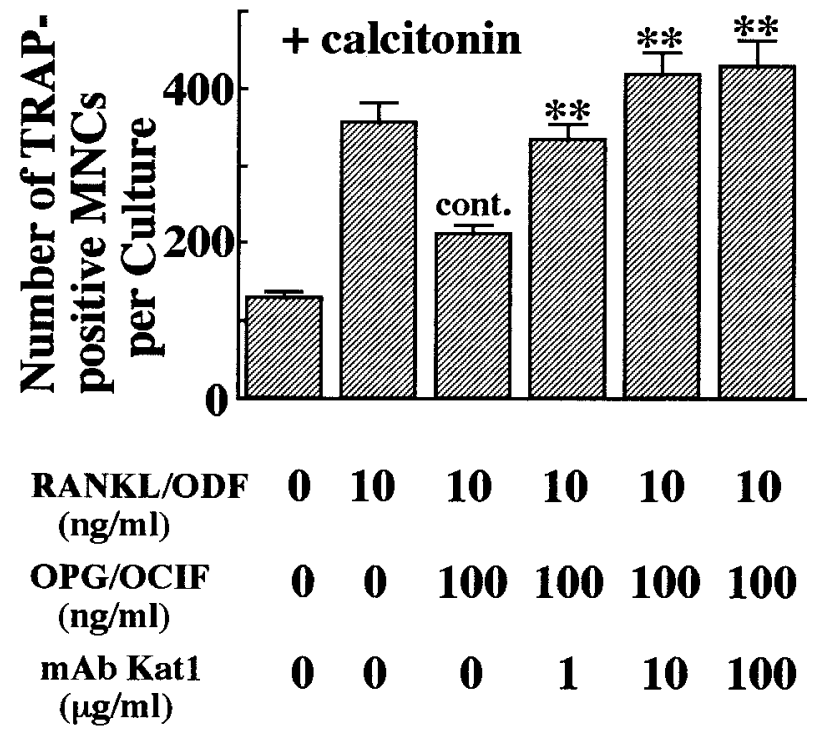

Figure 5 Marked stimulation of osteoclastogenesis by mAb Kat1 in the presence of $\mathrm{OPG} / \mathrm{OCIF}$, in cultures stimulated with RANKL/ODF. Bone marrow cells were cultured to form osteoclast-like MNCs as described in Materials and Methods in the presence of $1 \mathrm{ng} / \mathrm{ml}$ calcitonin with or without $10 \mathrm{ng} / \mathrm{ml}$ RANKL/ODF. These cultures were treated with various concentrations of mAb Kat1. After 1 day of culture, OPG/OCIF $(100 \mathrm{ng} / \mathrm{ml})$ was added and the cells cultured for up to 4 days. Cells were stained for TRAP and the number of TRAP-positive MNCs per culture counted. The mAb Kat1 markedly stimulated formation of osteoclast-like MNCs even in the presence of OPG/OCIF. Data show the mean number of TRAP-positive MNCs \pm S.E. from quadruplicate cultures in 24-well culture plates. Three independent experiments were performed and almost the same results obtained. ${ }^{*} P<0 \cdot 01$, based on data obtained in the presence of $10 \mathrm{ng} / \mathrm{ml}$ RANKL/ODF and $100 \mathrm{ng} / \mathrm{ml} \mathrm{OPG/OCIF} \mathrm{but}$ without $\mathrm{mAb}$ Kat1 (cont.).

a specific inhibitor of the interaction between RANKL/ ODF and RANK (Fig. 5). Osteoclastogenesis stimulated by RANKL/ODF was suppressed in the presence of OPG/OCIF. However, even in the presence of OPG/ OCIF, mAb Kat1 markedly stimulated the formation of osteoclast-like MNCs when cultures were treated with $1 \mathrm{ng} / \mathrm{ml}$ calcitonin. These osteoclast-like MNCs efficiently resorbed dentin (data not shown). This $\mathrm{mAb}$ Kat1-induced osteoclastogenesis was not inhibited by OPG/OCIF (Table 2).

A stimulatory effect of $\mathrm{mAb}$ Kat1 was also observed in bone marrow cultures treated with $100 \mathrm{ng} / \mathrm{ml} \mathrm{OPG/}$ OCIF in the absence of RANKL/ODF only when cultures were treated with calcitonin $(1 \mathrm{ng} / \mathrm{ml})$ (Fig. 6). Furthermore, treatment of osteoclast-like MNCs with a high concentration of RANKL/ODF $(500 \mathrm{ng} / \mathrm{ml}) \mathrm{did}$ not cause a significant change in the level of Kat1-Ag expression, as detected by immunocytochemical staining with mAb Kat1 (data not shown).

To determine the molecular size of the Kat1-Ag, we performed a Western blotting analysis under reducing
Table 2 Effect of OPG/OCIF on Kat1-Ag-mediated osteoclastogenesis. Bone marrow cells were cultured for forming osteoclast-like MNCs as described in Materials and Methods in the presence of $1 \mathrm{ng} / \mathrm{ml}$ caltitonin with or without $100 \mu \mathrm{g} / \mathrm{ml} \mathrm{mAb}$ Kat1. After 1 day of culture, cells were treated with OPG/OCIF and culture continued up to 4 days. Cells were stained for TRAP and the number of TRAP-positive MNCs counted. The number of TRAP-positive MNCs induced by mAb Kat1 was not decreased even in the presence of higher concentrations of OPG/OCIF

\begin{tabular}{|c|c|}
\hline $\begin{array}{l}\text { Number o } \\
\text { MNCs per }\end{array}$ & $\begin{array}{l}\text { AP-positive } \\
\text { ture }( \pm \text { S.E. })\end{array}$ \\
\hline $\begin{array}{l}\text { with } \\
\mathrm{mAb} \text { Kat1 }\end{array}$ & $\begin{array}{l}\text { without } \\
\text { mAb Kat1 }\end{array}$ \\
\hline
\end{tabular}

Number of mAb Kat-1 induced TRAP-positive MNCs per culture*

$\begin{aligned} & \text { OPG/OCIF } \\ & (\mathrm{ng} / \mathrm{ml})\end{aligned}$
0
50
100

$\begin{array}{ll}547 \cdot 5 \pm 44 \cdot 3 & 376 \cdot 7 \pm 9 \cdot 7 \\ 457 \cdot 0 \pm 37 \cdot 9 & 247 \cdot 7 \pm 17 \cdot 8 \\ 426 \cdot 7 \pm 33 \cdot 8 & 211 \cdot 5 \pm 12 \cdot 4\end{array}$

$170 \cdot 7$

$209 \cdot 2$

$215 \cdot 2$

*Number of mAb Kat1-induced TRAP-positive cells calculated as difference between the numbers with and without mAb Kat1 in the preceding columns.

conditions (Fig. 7). The cell lysate from osteoclast-like MNCs showed a single band of $32 \mathrm{kDa}$ that was specifically detected by mAb Kat1. In contrast, no band was detected in the cell lysate from ROS $17 / 2 \cdot 8$ cells, a rat osteoblastic cell line. These data demonstrate that the $32 \mathrm{kDa}$ protein is the molecular size of the Kat1-Ag in a reduced condition. These data strongly suggest that Kat1-Ag is a unique cell-surface antigen distinct from RANK.

\section{Discussion}

In the present study, we had expected some regulatory role of Kat1-Ag in osteoclastogenesis because we observed that osteoclast-like MNCs frequently adhered to mononuclear cells expressing Kat1-Ag and that mononuclear cells expressing Kat1-Ag frequently interacted with each other. In the absence of calcitonin, treatment of cultures with mAb Kat1 had no effect on MNC formation. However, in the presence of calcitonin, mAb Kat1 treatment caused a marked increase in the formation of osteoclast-like MNCs. Such a stimulatory effect was observed even at lower concentrations $(0 \cdot 01-1 \mathrm{ng} / \mathrm{ml})$ of calcitonin. Calcitonin is known to inhibit osteoclast formation in various cultures that are used for assessing osteoclastogenesis (MacDonald et al. 1986, Takahashi et al. 1988). Higher concentrations of calcitonin (more than $10 \mathrm{ng} / \mathrm{ml}$ ) are required to express an inhibitory effect on osteoclast formation. In the current study, it was surprising to find that mAb Kat1 stimulated formation of osteoclast-like MNCs only in the presence of calcitonin. Few reports have investigated osteoclastogenesis in the presence of calcitonin. There might be some 

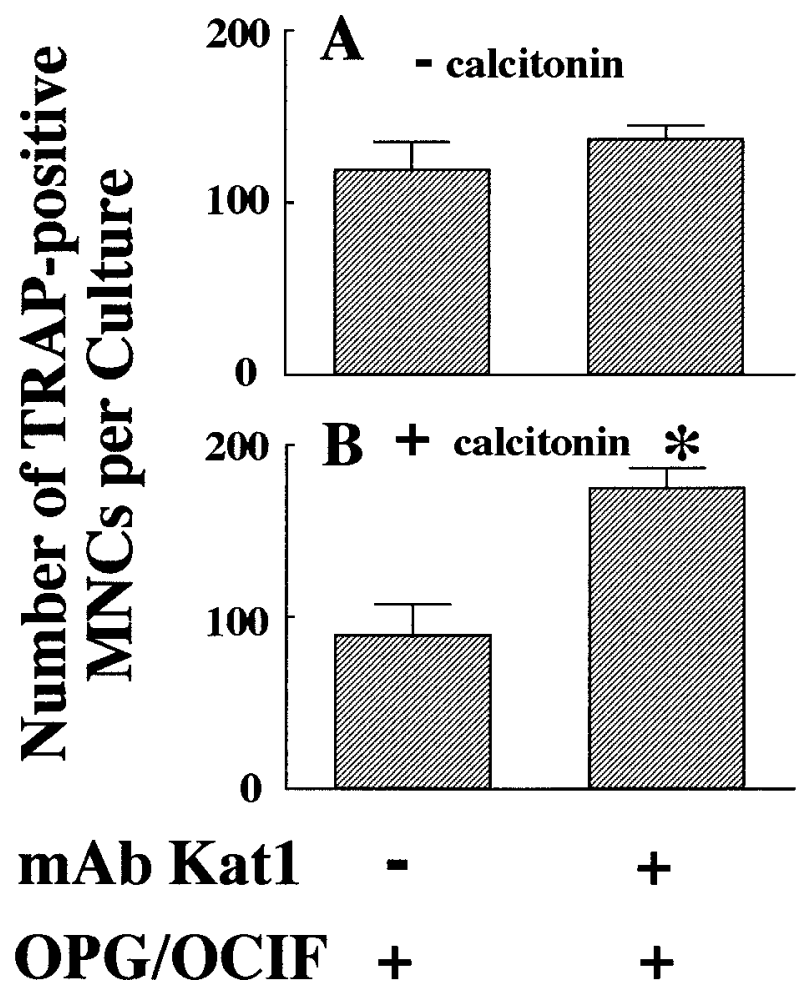

Figure 6 Stimulation of osteoclastogenesis by mAb Kat1 in the presence of OPG/OCIF, in cultures not stimulated with RANKL/ODF. Bone marrow cells were cultured to form osteoclast-like MNCs as described in Materials and Methods in the presence of $100 \mathrm{ng} / \mathrm{ml}$ OPG/OCIF with (B) or without (A) $1 \mathrm{ng} / \mathrm{ml}$ calcitonin. Cultures were treated $(+)$ or untreated $(-)$ with mAb Kat 1 and cultured for 4 days. Cells were stained for TRAP and the number of TRAP-positive MNCs counted. The mAb Kat1 significantly stimulated osteoclast-like MNC formation only in the presence of calcitonin even in the presence of $100 \mathrm{ng} / \mathrm{ml}$ OPG/OCIF. Data show the mean number of TRAP-positive MNCs \pm S.E. from quadruplicate cultures in 24-well culture plates. Three independent experiments were performed and almost the same results obtained. ${ }^{*} P<0 \cdot 05$ compared with cells cultured without mAb Kat1.

interactions between CTR, Kat1-Ag and the putative fusion machinery required for osteoclastogenesis, which are expressed on the surface of cells in the osteoclast lineage. However, such stimulatory effects were not observed when cells were treated with higher concentrations of $\mathrm{mAb}$ Kat1. Previously, we have demonstrated that in the presence of $10 \mathrm{ng} / \mathrm{ml} \mathrm{mAb} \mathrm{Kat1,} \mathrm{even} \mathrm{lower}$ concentrations $(0 \cdot 1-1 \mathrm{ng} / \mathrm{ml})$ of calcitonin inhibited formation of osteoclast-like MNCs. In our current experiments, similar suppressive effects of calcitonin on osteoclastogenesis were observed when cells were treated with $100 \mathrm{ng} / \mathrm{ml} \mathrm{mAb} \mathrm{Kat1.} \mathrm{Such} \mathrm{a} \mathrm{difference} \mathrm{in} \mathrm{the} \mathrm{effective}$ concentrations of $\mathrm{mAb}$ Kat1 from our previous report is supposed to be attributed to a difference in the immunological titer of each antibody preparations. As the formation of mononuclear preosteoclasts was not significantly
$\operatorname{Mr} \times \begin{array}{llllll}10 & 1 & 2 & 3 & 4\end{array}$

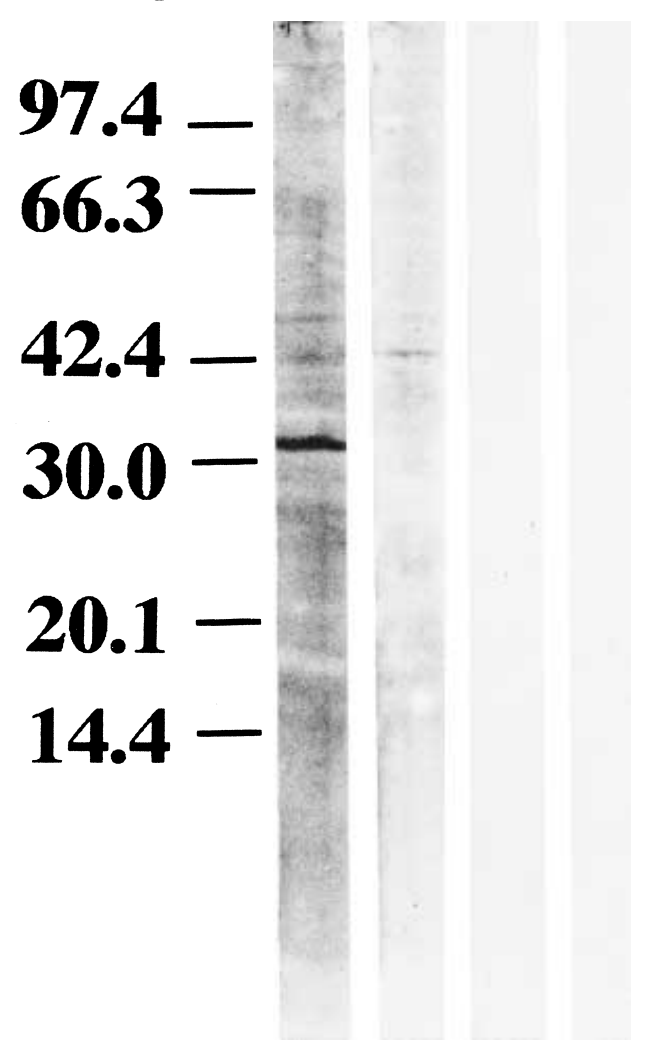

Figure 7 Western blotting analysis of the Kat1-Ag under reducing conditions. Cells were cultured and treated with $10 \%$ trichloroacetic acid, followed by preparation of samples for SDS-PAGE under reducing conditions as described in Materials and Methods. After immunoblotting the proteins onto the nitrocellulose, they were reacted with mAb Kat1 (lanes 1 and 2) or with control mAb (lanes 3 and 4) followed by detection with an ABC-AP kit. Lane 1 and lane 3, cell lysates from osteoclast-like MNCs; lanes 2 and 4, cell lysates from ROS 17/2.8 cells. mAb Kat1 specifically detected a clear single band having a molecular mass of $32 \mathrm{kDa}$ in cell lysates from osteoclast-like MNCs (lane 1) but not in lysates of ROS $17 / 2 \cdot 8$ cells (lane 2 ). No band was detected with the control antibody (lanes 3 and 4).

affected by mAb Kat1, in either the presence or absence of calcitonin, the following fusion process of preosteoclasts was supposed to be a target step in Kat1-Ag-mediated regulation of osteoclastogenesis in the presence of calcitonin. The fusion efficiency of the preosteoclasts was supposed to be augmented by treatment with mAb Kat1 and calcitonin. Treatment of human peripheral blood cultures with anti-CD98 $\mathrm{mAb}$ induces the formation of osteoclast-like MNCs (Higuchi et al. 1998). Antimacrophage-fusion-receptor $\mathrm{mAb}$ inhibits the fusion of peritoneal macrophages when these cells are cultured to form macrophage polykaryons (Saginario et al. 1998). 


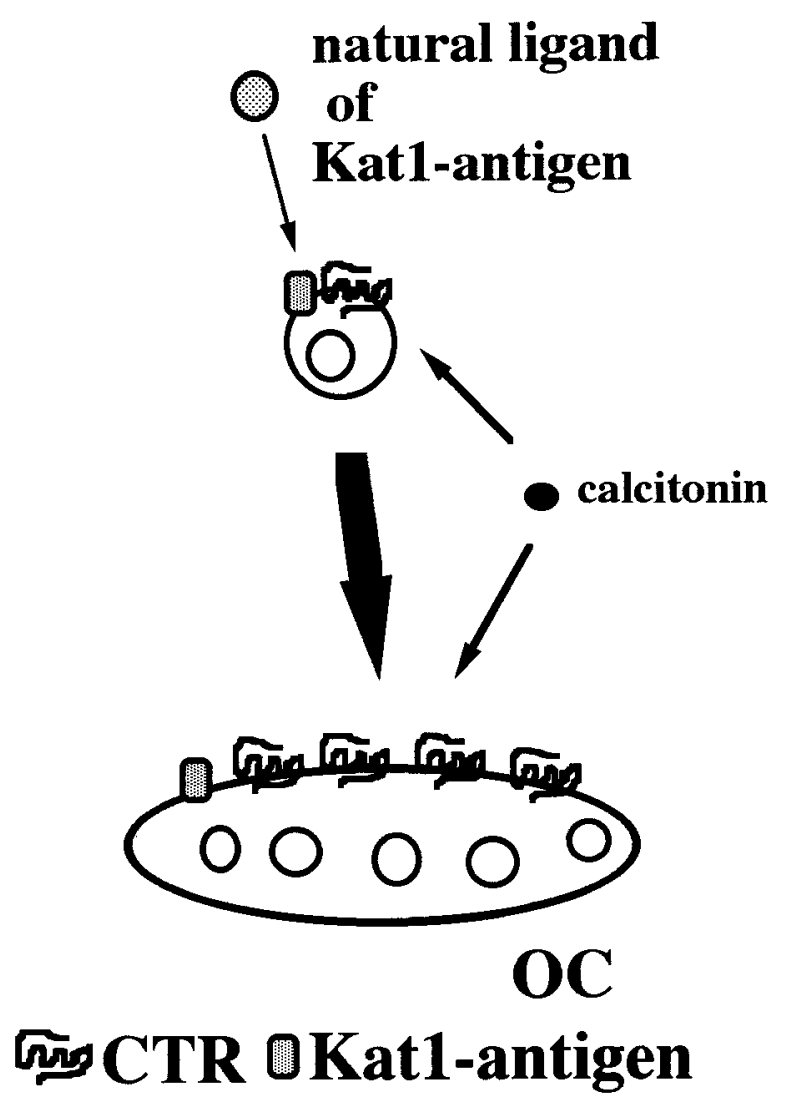

Figure 8 Regulation of osteoclastogenesis through Kat1-Ag - a hypothesis. A putative natural ligand of the Kat1-Ag binds to Kat1-Ag expressed on the surface of cells in the osteoclast (OC) lineage and this ligand stimulates osteoclastogenesis in the presence of calcitonin.

However, to our knowledge, no one has yet reported cell-surface molecules being involved in osteoclast formation only under suppressed conditions mediated by calcitonin. Such a mechanism for regulating osteoclastogenesis needs to be further investigated to understand the cell biology of osteoclasts.

The escape phenomenon is a clinically defined event, in which calcitonin treatments become ineffective after bone cells are exposed to pharmacological concentrations of calcitonin. Our data may provide cell-biological evidence suggesting that the escape phenomenon involves the formation of osteoclasts. An increase in the number of newly formed osteoclasts could diminish the inhibitory effect of administered calcitonin and it could participate in the occurrence of the calcitonin-mediated escape phenomenon. Although our experiments were only performed in vitro with $\mathrm{mAb}$ Kat1, we assume that stimulation of Kat1-Ag by the natural ligand for this antigen would lead to a result similar to that when cells were treated with mAb Kat1 (Fig. 8). We expect that our culture conditions containing low concentrations of calcitonin $(0 \cdot 01 \mathrm{ng} / \mathrm{ml})$ could partly reflect the hormonal environments observed in vivo, as the upper normal level of serum calcitonin is approximately $0.03 \mathrm{ng} / \mathrm{ml}$ (Mallette \& Gagel 1993). When osteoclastic bone resorption is directly inhibited by calcitonin, formation of osteoclasts may be provoked through the Kat1-Ag-mediated signal in osteoclast precursors in vivo. These newly formed osteoclasts are thought to diminish the inhibitory effect of administered calcitonin on osteoclastic bone resorption.

RANKL/ODF is a membrane-bound cytokine that induces osteoclastogenesis as well as osteoclast activation (Burgess 1999, Jimi et al. 1999). Hsu et al. (1999) recently reported about the induction of osteoclastogenesis when cell-surface RANK molecules expressed on osteoclast progenitors were cross-linked by anti-RANK antibody, even in the absence of RANKL/ODF. Therefore we examined the possibility that Kat1-Ag is RANK. However, our current data indicate that there is a clear difference between Kat1-Ag and RANK. Even in the presence of inhibitory concentrations of OPG/OCIF, $\mathrm{mAb}$ Kat1 markedly stimulated the formation of osteoclast-like MNCs in the presence of calcitonin. A Western blotting analysis revealed that the Kat1-Ag has a molecular mass around $32 \mathrm{kDa}$ under reducing conditions. The molecular mass of RANK, which is around $110 \mathrm{kDa}$, strongly suggests that Kat1-Ag is a unique cell-surface antigen completely distinct from RANK. Recently, lines of evidence showed that TNF- $\alpha$ induces osteoclastogenesis in a mechanism independent from the RANKL/ ODF-RANK system (Azuma et al. 2000, Kobayashi et al. 2000, Komine et al. 2001). The current study also showed a possible mechanism of osteoclastogenesis independent from the RANKL/ODF-RANK system.

Further studies are needed to characterize the Kat1-Ag as well as its natural ligand. Our observations will open the way to develop new strategies to suppress the calcitoninmediated escape phenomenon. As calcitonin is widely utilized and calcitonin treatments of metabolic bone diseases are considered to be among the safest therapies, development of a method for regulating Kat1-Ag may lead to calcitonin-based novel therapies against metabolic bone diseases.

\section{Acknowledgements}

The authors thank Dr James Raymond for correcting English usage in this manuscript. This work was supported in part by a Grant for Scientific Research from the Japanese Ministry of Education, Science and Culture (Project 09671858).

\section{References \\ Anderson DM, Maraskovsky E, Billingsley WL, Dougall WC, Tometsko ME, Roux ER, Teepe MC, DuBose RF, Cosman D \&}


Galibert L 1997 A homologue of the TNF receptor and its ligand enhance T-cell growth and dendritic-cell function. Nature $\mathbf{3 9 0}$ $175-179$.

Azuma Y, Kaji K, Katogi R, Takeshita S \& Kudo A 2000 Tumor necrosis factor-alpha induces differentiation of and bone resorption by osteoclasts. Journal of Biological Chemistry 275 4858-4864.

Burgess TL, Qian Y, Kaufman S, Ring BD, Van G, Capparelli C, Kelley M, Hsu H, Boyle WJ, Dunstan CR, Hu S \& Lacey DL 1999 The ligand for osteoprotegerin (OPGL) directly activates mature osteoclasts. Journal of Cell Biology 145 527-538.

Copp DH, Cameron EC, Cheney BA, Davidson AGF \& Heaze KG 1962 Evidence for calcitonin - a new hormone from the parathyroid that lowers blood calcium. Endocrinology 70 638-649.

Findlay DM \& Martin TJ 1997 Receptors of calciotropic hormones. Hormone and Metabolic Research 29 128-134.

Heersche JN 1992 Calcitonin effects on osteoclastic resorption: the 'escape phenomenon' revisited. Bone and Mineral 16 174-177.

Higuchi S, Tabata N, Tajima M, Ito M, Tsurudome M, Sudo A, Uchida A \& Ito Y 1998 Induction of human osteoclast-like cells by treatment of blood monocytes with anti-fusion regulatory protein-1/CD98 monoclonal antibodies. Journal of Bone and Mineral Research 13 44-49.

Hsu H, Lacey DL, Dunstan CR, Solovyev I, Colombero A, Timms E, Tan HL, Elliott G, Kelley MJ, Sarosi I, Wang L, Xia XZ, Elliott R, Chiu L, Black T, Scully S, Capparelli C, Morony S, Shimamoto G, Bass MB \& Boyle WJ 1999 Tumor necrosis factor receptor family member RANK mediates osteoclast differentiation and activation induced by osteoprotegerin ligand. PNAS 96 3540-3545.

Ikegame M, Ejiri S \& Ozawa H 1994 Histochemical and autoradiographic studies on elcatonin internalization and intracellular movement in osteoclasts. Journal of Bone and Mineral Research 9 $25-37$.

Jimi E, Akiyama S, Tsurukai T, Okahashi N, Kobayashi K, Udagawa N, Nishihara T, Takahashi N \& Suda T 1999 Osteoclast differentiation factor acts as a multifunctional regulator in murine osteoclast differentiation and function. Journal of Immunology 163 434-442.

Kallio DM, Garant PR \& Minkin C 1972 Ultrastructural effects of calcitonin on osteoclasts in tissue culture. Journal of Ultrastructure Research 39 205-216.

Kobayashi K, Takahashi N, Jimi E, Udagawa N, Takami M, Kotake S, Nakagawa N, Kinosaki M, Yamaguchi K, Shima N, Yasuda H, Morinaga T, Higashio K, Martin TJ \& Suda T 2000 Tumor necrosis factor alpha stimulates osteoclast differentiation by a mechanism independent of the RANKL/ODF-RANK interaction. Journal of Experimental Medicine 191 275-286.

Komine M, Kukita A, Kukita T, Hotokebuchi T \& Kohashi O 2001 Tumor necrosis factor $\alpha$ cooperates with receptor activator of nuclear factor $\mathrm{\kappa B}$ ligand in generation of osteoclasts in stromal cell depleted rat bone marrow cell culture. Bone 28 474-483.

Kong Y-Y, Yoshida H, Sarosi I, Tan H-L, Timms E, Capparelli C, Morony S, Oliveira-dos-Santos AJ, Van G, Itie A, Khoo W, Wakeham A, Dunstan CR, Lacey DL, Mak TW, Boyle WJ \& Penninger JM 1999 OPGL is a key regulator of osteoclastogenesis, lymphocyte development and lymph-node organogenesis. Nature 397 315-323.

Krieger NS, Feldman RS \& Tashjian AH Jr 1982 Parathyroid hormone and calcitonin interactions in bone: irradiation-induced inhibition of escape in vitro. Calcified Tissue International 34 197-203.

Kukita A, Kukita T, Hata K, Kurisu K \& Kohashi O 1993 Heat-treated osteoblastic cell (ROS 17/2.8)-conditioned medium induces the formation of osteoclast-like cells. Bone and Mineral 23 $113-127$.

Kukita T, Kukita A, Nagata K, Maeda H, Kurisu K, Watanabe T \& Iijima T 1994 Novel cell-surface Ag expressed on rat osteoclasts regulating the function of the calcitonin receptor. Journal of Immunology 153 5265-5273.

Kukita T, Kukita A, Xu L \& Iijima T 1998 Successful detection of active osteoclasts in situ by systemic administration of an osteoclast-specific monoclonal antibody. Calcified Tissue International 63 148-153.

Lacey DL, Timms E, Tan H-L, Kelley MJ, Dunstan CR, Burgess T, Elliott R, Colombero A, Elliott G, Scully S, Hsu H, Sullivan J, Hawkins N, Davy E, Capparelli C, Eli A, Qian Y-X, Kaufman S, Sarosi I, Shalhoub V, Senaldi G, Guo J, Delaney J \& Boyle WJ 1998 Osteoprotegerin ligand is a cytokine that regulates osteoclast differentiation and activation. Cell 93 165-176.

Lin HY, Harris TL, Flannery MS, Aruffo A, Kaji EH, Gorn A, Kolakowski LF Jr, Lodish HF \& Goldring SR 1991 Expression cloning of an adenylate cyclase-coupled calcitonin receptor. Science 254 1022-1024.

MacDonald BR, Mundy GR, Clark S, Wang EA, Kuehl TJ, Stanley ER \& Roodman GD 1986 Effects of human recombinant CSF-GM and highly purified CSF-1 on the formation of multinucleated cells with osteoclast characteristics in long-term bone marrow cultures. Journal of Bone and Mineral Research 1 227-233.

Mallette LE \& Gagel RF 1993 Parathyroid hormone and calcitonin. In Primer on the Metabolic Bone Diseases and Disorders of Mineral Metabolism, edn 1, pp 90-99. Ed MJ Favus. New York: Raven Press.

Minkin C, Reynolds JJ \& Copp HC 1971 Inhibitory effect of salmon and other calcitonins on calcium release from mouse bone in vitro. Canadian Journal of Physiology and Pharmacology 49 263-267.

Nakamura T, Toyofuku F \& Kanda S 1985 Whole-body irradiation inhibits the escape phenomenon of osteoclasts in bones of calcitonin-treated rats. Calcified Tissue International 37 42-45.

Saginario C, Sterling H, Beckers C, Kobayashi R, Solimena M, Ullu E \& Vignery A 1998 MFR, a putative receptor mediating the fusion of macrophages. Molecular and Cellular Biology 18 6213-6223.

Simonet WS, Lacey DL, Dunstan CR, Kelley M, Chang M-S, Luthy R, Nguyen HQ, Wooden S, Bennett L, Boone T, Shimamoto G, DeRose M, Elliott R, Colombero A, Tan H-L, Trail G, Sullivan J, Davy E, Bucay N, Renshaw-Gegg L, Hughes TM, Hill D, Pattison W, Campbell P, Boyle WJ et al. 1997 Osteoprotegerin: a novel secreted protein involved in the regulation of bone density. Cell 89 309-319.

Takahashi N, Yamana H, Yoshiki S, Roodman GD, Mundy GR, Jones SJ, Boyde A \& Suda T 1988 Osteoclast-like cell formation and its regulation by osteotropic hormones in mouse bone marrow cultures. Endocrinology 122 1373-1382.

Takahashi S, Goldring S, Katz M, Hilsenbeck S, Williams R \& Roodman GD 1995 Downregulation of calcitonin receptor mRNA expression by calcitonin during human osteoclast-like cell differentiation. Journal of Clinical Investigation 95 167-171.

Wener JA, Gorton SJ \& Raisz LG 1972 Escape from inhibition or resorption in cultures of fetal bone treated with calcitonin and parathyroid hormone. Endocrinology 90 752-759.

Yasuda H, Shima N, Nakagawa N, Yamaguchi K, Kinosaki M, Mochizuki S, Tomoyasu A, Yano K, Goto M, Murakami A, Tsuda E, Morinaga T, Higashio K, Udagawa N, Takahashi N \& Suda T 1998 Osteoclast differentiation factor is a ligand for osteoprotegerin/osteoclastogenesis-inhibitory factor and is identical to TRANCE/RANKL. PNAS 95 3597-3602.

Received 16 February 2001

Accepted 7 March 2001 